\title{
Combination of C-reactive Protein and High Molecular Weight (HMW)-Adiponectin Reflects Further Metabolic Abnormalities Compared with Each of Them Alone in Japanese Type 2 Diabetic Subjects
}

\author{
YoSHIFUMI SAISHO, HIROSHI HIROSE, YUKIHIRO YAMAMOTO, HIROSHI NAKATANI AND HIROSHI ITOH
}

Department of Internal Medicine, Keio University School of Medicine, 35 Shinanomachi, Shinjuku-ku, Tokyo 160-8582, Japan

\begin{abstract}
Objective: Serum C-reactive protein (CRP) and adiponectin levels predict atherosclerosis and coronary heart disease. However, the efficacy of the combination of both markers remains unknown. In the present study, we investigated whether the combination of CRP and adiponectin is associated with further metabolic abnormalities compared to each of them alone. Research design and methods: Eighty-three Japanese type 2 diabetic outpatients participated in this study. We measured serum high-sensitive CRP and high molecular weight (HMW)-adiponectin, and investigated their relationship with various metabolic parameters. Results: In univariate analysis, CRP was significantly correlated with diastolic blood pressure and HDL-cholesterol. On the other hand, HMW-adiponectin was significantly correlated with systolic (SBP) and diastolic blood pressure, plasma glucose, HDL-cholesterol, triglycerides and HOMA-IR, but not with CRP. We then classified the subjects into three groups: low CRP and high HMW-adiponectin levels (low risk group, 19\%), high CRP and low HMW-adiponectin levels (high risk group, 22\%), and others. In Spearman rank correlation coefficient analysis, this classification was significantly associated with a larger number of metabolic risk factors: SBP, glucose, HbA1c, LDL-cholesterol, HDL-cholesterol, triglycerides and HOMA-IR, compared with classification by CRP or HMW-adiponectin alone. Conclusion: These results suggest that combination of CRP and HMW-adiponectin reflects further metabolic abnormalities compared with each of them in type 2 diabetic subjects. The combined measurement of both markers may be useful to detect cardiovascular high risk patients.
\end{abstract}

Key words: C-reactive protein, Adiponectin, Coronary risk factor, Type 2 diabetes mellitus

(Endocrine Journal 55: 331-338, 2008)

BOTH type 2 diabetes and atherosclerosis are characterized by low-grade inflammation and insulin

Received: August 25, 2007

Accepted: December 17, 2007

Correspondence to: Hiroshi HIROSE, M.D., Ph.D., Department of Internal Medicine, Keio University School of Medicine, 35 Shinanomachi, Shinjuku-ku, Tokyo 160-8582, Japan

Abbreviations: CRP, C-reactive protein; BMI, body mass index; HDL, high-density lipoprotein; LDL, low-density lipoprotein; HOMA-IR, homeostasis model assessment insulin resistance index; CHD, coronary heart disease; SBP, systolic blood pressure; DBP, diastolic blood pressure; HMW, high molecular weight; ELISA, enzyme-linked immunosorbent assay; SU, sulfonylureas; TZD, thiazolidinedione; IMT, intima-media thickness; PWV, pulse-wave velocity resistance $[1,2]$. Patients with type 2 diabetes show a 2 - to 5 -fold increase in coronary heart disease (CHD)related death [3], thus it is very important to precisely evaluate the risk of CHD in diabetic patients in clinical settings. Serum CRP and adiponectin reflect low-grade inflammation and insulin resistance, respectively, and are known as the important markers of atherosclerosis and CHD $[4,5]$.

Serum CRP level is increased in obese [6] and diabetic [7-9] subjects, and predicts the onset of cardiovascular disease [4, 10-12]. On the other hand, serum adiponectin level is negatively associated with visceral fat [13] and insulin resistance [13-15]. It has been reported that adiponectin level is decreased in obese [16] and diabetic subjects [17] and subjects with cardiovas- 
cular disease [17]. It has also been reported that a low serum adiponectin level is associated with increased risk of myocardial infarction [18] and predicts the progression of coronary artery calcification [19]. Recently, high molecular weight (HMW)-adiponectin and HMW-adiponectin/total adiponectin ratio rather than total adiponectin have been reported to be useful for evaluation of coronary artery disease [20] or insulin resistance [21] in the subjects with type 2 diabetes. It has also been reported that HMW-, but not low molecular weight, adiponectin selectively decreases in the subjects with type 2 diabetes [22], suggesting that HMWadiponectin plays an important role in the development of cardiovascular disease.

A negative correlation between serum CRP and adiponectin levels in non-diabetic [18, 23-27] and diabetic subjects $[9,20,28-31]$ has been reported, and it is well-recognized that obesity is associated with both insulin resistance and inflammation, leading to atherosclerosis [32]. However, the precise mechanism of this correlation between CRP and adiponectin remains unclear. Others have shown no significant relation between CRP and adiponectin [33-35]. Furthermore, recent studies have shown that CRP is associated with obesity rather than insulin resistance or metabolic syndrome [36-38]. These results indicate a possibility of some different aspects between low-grade inflammation and insulin resistance, and suggest a synergistic effect of these two factors on atherosclerosis. Nonetheless, no report has examined the efficacy of the combination of serum CRP and adiponectin compared to each of them alone. In the present study, we investigated whether or not the combination of CRP and HMW-adiponectin is associated with further metabolic abnormality in type 2 diabetic subjects compared to each of them alone.

\section{Patients and Methods}

\section{Subjects}

We measured serum levels of CRP, HMW-adiponectin and other metabolic parameters in 83 (51 men and 32 post-menopausal women, age $63 \pm 8$ years, duration of diabetes $7.8 \pm 5.4$ years, Table 1) Japanese type 2 diabetic patients in the outpatient clinic of Keio University Hospital, Tokyo, Japan. Patients were treated with dietary therapy and/or oral hypoglycemic
Table 1. Clinical and laboratory characteristics of the patients

\begin{tabular}{lcc}
\hline $\mathrm{N}(\mathrm{M} / \mathrm{F})$ & & $83(51 / 32)$ \\
Age & $($ years $)$ & $63 \pm 8$ \\
Duration of diabetes & $($ years $)$ & $7.8 \pm 5.4$ \\
Current smoking & $(\%)$ & 28.9 \\
BMI & $\left(\mathrm{kg} / \mathrm{m}^{2}\right)$ & $23.6 \pm 3.2$ \\
Systolic blood pressure & $(\mathrm{mmHg})$ & $129 \pm 17$ \\
Diastolic blood pressure & $(\mathrm{mmHg})$ & $77 \pm 11$ \\
Glucose & $(\mathrm{mmol} / \mathrm{L})$ & $7.7 \pm 1.5$ \\
HbA1c & $(\%)$ & $6.4 \pm 0.9$ \\
LDL-cholesterol & $(\mathrm{mg} / \mathrm{dL})$ & $121 \pm 25$ \\
HDL-cholesterol & $(\mathrm{mg} / \mathrm{dL})$ & $56 \pm 13$ \\
Triglyceride & $(\mathrm{mg} / \mathrm{dL})$ & $107 \pm 55$ \\
Insulin & $(\mu \mathrm{U} / \mathrm{mL})$ & $7.0 \pm 5.9$ \\
HOMA-IR & - & $2.43 \pm 2.12$ \\
CRP & $(\mathrm{mg} / \mathrm{dL})$ & $0.075 \pm 0.090$ \\
HMW-adiponectin & $(\mu \mathrm{g} / \mathrm{mL})$ & $4.7 \pm 3.2$ \\
\hline
\end{tabular}

Values are means \pm SD.

agents, but not with insulin. We recruited the subjects who had not been changed any diet or medication therapy for at least 3 months and glycemic control was relatively stable for this period (mean HbAlc $6.4 \pm 0.9 \%$, Table 1). The present study was conducted according to the principles expressed in the Declaration of Helsinki. Informed consent was obtained from each patient after full explanation of the purpose, nature and risk of all procedures used. The protocol was approved by the ethical review committee of the Department of Internal Medicine, Keio University School of Medicine, Tokyo, Japan.

Thirty-eight (46\%) patients were treated with dietary therapy only, and the others were treated with one or more oral hypoglycemic agents. Forty (48\%) patients were treated with sulfonylureas (SU), $30(36 \%)$ with alpha-glucosidase inhibitors, and $6(7 \%)$ with biguanides. Patients treated with thiazolidinediones (TZD) were excluded from the study. The duration of diabetes and smoking habit were obtained from medical records or questionnaires to the patients.

Fifteen patients (18\%) had diabetic retinopathy documented by ophthalmologists, and 9 patients $(11 \%)$ had diabetic nephropathy with micro-albuminuria or proteinuria. Thirty-three patients $(40 \%)$ had hypertension, and 21 patients $(25 \%)$ were being treated with antihypertensive medicine. Seventeen patients $(20 \%)$ were being treated with a statin for hyperlipidemia. Eight patients $(10 \%)$ had macroangiopathy; 7 with myocardial infarction and 1 with cerebral infarction. Patients who had hepatitis or liver cirrhosis, renal 
failure $(\mathrm{Cr}>1.9 \mathrm{mg} / \mathrm{dL}$ ), inflammatory disease (or CRP $>1 \mathrm{mg} / \mathrm{dL}$ ) or malignancy were excluded from the study.

\section{Measurements}

Systolic blood pressure (SBP) and diastolic blood pressure (DBP) were measured with subjects in the sitting position after resting for at least $5 \mathrm{~min}$. Blood samples were collected in the morning after an overnight fast.

Serum glucose was measured by glucose oxidase method. Serum insulin was measured as immunoreactive insulin by enzyme immunoassay. Low-density lipoprotein (LDL)-cholesterol, triglycerides and highdensity lipoprotein (HDL)-cholesterol levels were determined using standard laboratory methods [14, 15].

Serum CRP level was measured by nephelometry, a latex particle-enhanced immunoassay (N Latex CRP II, Dade Behring, Tokyo, Japan) with both intra- and inter-assay coefficients of variation of $<5.0 \%$. The assay could detect $0.005 \mathrm{mg} / \mathrm{dL}$ of CRP.

Insulin resistance index was assessed using homeostasis model assessment (HOMA-IR), which was calculated as follows: HOMA-IR $=$ (insulin $(\mu \mathrm{U} /$ $\mathrm{mL}) \times$ plasma glucose $(\mathrm{mmol} / \mathrm{L})) / 22.5$.

\section{Measurement of HMW-adiponectin by ELISA}

HMW-adiponectin was measured using a commercially available kit (HMW Adiponectin ELISA Kit, Fujirebio Co. Inc., Tokyo, Japan). This ELISA system does not need a denaturing step, and the antibody reacts specifically with the HMW form of adiponectin [39]. The dilution curve was parallel to the standard curve. Intra- and inter-assay coefficients were $2.4-3.0 \%$ and $4.2-5.1 \%$, respectively.

\section{Statistical analysis}

All statistical analyses were performed using the StatView program for Windows (version 5.0-J; SAS Institute Inc., Cary, NC, USA). Mann-Whitney U-test and Kruskal-Wallis test were used for comparison of metabolic parameters among two or three groups, respectively. Relationships between serum CRP or HMW-adiponectin level and other parameters were analyzed by simple correlation and multiple linear regressions. Spearman rank correlation coefficient was used to analyze the correlation with metabolic parameters among the three classified groups. Because serum triglycerides, insulin, HOMA-IR, CRP and HMW-adiponectin were normally distributed after logarithmic transformation, the logarithms of these parameters were used for the analyses. All data are expressed as mean \pm S.D., and values of $\mathrm{P}<0.05$ were considered statistically significant.

\section{Results}

\section{Characteristics of patients}

Characteristics of the patients are shown in Table 1. Mean CRP and HMW-adiponectin concentrations were $0.075 \pm 0.090 \mathrm{mg} / \mathrm{dL}$ and $4.7 \pm 3.2 \mu \mathrm{g} / \mathrm{mL}$, respectively. CRP and HMW-adiponectin tended to be lower and higher, respectively, in female patients, while the differences between male and female patients were not significant (CRP; $0.083 \pm 0.106$ vs. $0.063 \pm 0.054$ $\mathrm{mg} / \mathrm{dL}, \mathrm{P}=0.52$, HMW-adiponectin; $4.1 \pm 2.7$ vs. $5.6 \pm 3.8 \mu \mathrm{g} / \mathrm{mL}, \mathrm{P}=0.07$ in male vs. female, respectively). There was no significant difference in both CRP and HMW-adiponectin between the patients with and without statin treatment $(0.056 \pm 0.034$ vs. $0.080 \pm 0.099 \mathrm{mg} / \mathrm{dL}, \quad \mathrm{P}=0.80$ and $5.0 \pm 3.3$ vs. $4.6 \pm 3.3 \mu \mathrm{g} / \mathrm{mL}, \mathrm{P}=0.66$ in $\mathrm{CRP}$ and HMW-adiponectin, respectively).

\section{Correlations of CRP and HMW-adiponectin with met- abolic parameters}

The correlations of serum CRP and HMW-adiponectin levels with other parameters in all patients are shown in Table 2. In univariate analysis, CRP showed a significant positive correlation with DBP $(r=0.245)$, and a significant negative correlation with HDLcholesterol $(\mathrm{r}=-0.290)$. CRP also showed positive correlations with BMI $(r=0.184)$, SBP $(r=0.182)$ and triglycerides $(\mathrm{r}=0.187)$, while the correlations did not reach statistical significance $(\mathrm{P}=0.1)$. But there was no correlation between CRP and HOMA-IR $(r=0.092)$. Even after adjustment for age and sex, the correlations of CRP with DBP and HDL-cholesterol remained significant.

On the other hand, HMW-adiponectin showed significant negative correlations with SBP $(\mathrm{r}=-0.266)$, DBP $(r=-0.264)$, glucose $(r=-0.270)$, triglycerides 
Table 2. Correlations of CRP and HMW-adiponectin with other parameters

\begin{tabular}{|c|c|c|c|c|c|c|c|c|}
\hline & \multicolumn{4}{|c|}{ CRP $(\log )$} & \multicolumn{4}{|c|}{ HMW-adiponectin $(\log )$} \\
\hline & \multicolumn{5}{|c|}{ after adjustment ${ }^{\mathrm{a}}$} & \multicolumn{3}{|c|}{ after adjustment $^{\mathrm{a}}$} \\
\hline & $\mathrm{r}$ & $P$ & $\mathrm{r}$ & $P$ & $\mathrm{r}$ & $P$ & $\mathrm{r}$ & $P$ \\
\hline BMI & 0.184 & 0.10 & 0.179 & 0.11 & -0.093 & 0.40 & -0.079 & 0.47 \\
\hline Systolic blood pressure & 0.182 & 0.10 & 0.182 & 0.11 & -0.266 & 0.02 & -0.228 & 0.04 \\
\hline Diastolic blood pressure & 0.245 & 0.03 & 0.253 & 0.03 & -0.264 & 0.02 & -0.227 & 0.05 \\
\hline Glucose & 0.163 & 0.14 & 0.167 & 0.15 & -0.270 & 0.01 & -0.236 & 0.03 \\
\hline HbAlc & 0.090 & 0.42 & 0.112 & 0.34 & -0.196 & 0.08 & -0.215 & 0.06 \\
\hline LDL-cholesterol & -0.005 & 0.96 & 0.006 & 0.96 & -0.164 & 0.14 & -0.193 & 0.08 \\
\hline HDL-cholesterol & -0.290 & 0.008 & -0.306 & 0.009 & 0.293 & 0.007 & 0.245 & 0.03 \\
\hline Triglyceride (log) & 0.187 & 0.09 & 0.190 & 0.09 & -0.239 & 0.03 & -0.225 & 0.04 \\
\hline Insulin $(\log )$ & 0.047 & 0.68 & 0.051 & 0.66 & -0.189 & 0.10 & -0.196 & 0.08 \\
\hline HOMA-IR (log) & 0.092 & 0.42 & 0.091 & 0.43 & -0.269 & 0.02 & -0.266 & 0.02 \\
\hline CRP $(\log )$ & - & - & - & - & -0.033 & 0.77 & -0.021 & 0.85 \\
\hline
\end{tabular}

Pearson's correlation coefficient. a Adjustment for age and sex.

$(\mathrm{r}=-0.239)$ and HOMA-IR $(\mathrm{r}=-0.269)$, but not BMI $(\mathrm{r}=-0.093)$, and a significant positive correlation with HDL-cholesterol $(\mathrm{r}=0.293)$. These correlations, except that for DBP, remained significant even after adjustment for age and sex. There was no significant correlation between CRP and adiponectin $(\mathrm{r}=-0.033$, $\mathrm{P}=0.77$, Fig. 1). Even when we excluded the subjects treated with either statins or SU, there was no correlation between CRP and HMW-adiponectin $(\mathrm{r}=-0.019$, $\mathrm{P}=0.88$ and $\mathrm{r}=0.090, \mathrm{P}=0.56$, respectively).

\section{Classification by combination of CRP and HMW- adiponectin}

We then divided the patients into each quartile of CRP and HMW-adiponectin levels, respectively, and scored the values as shown in Table 3. The classifica-

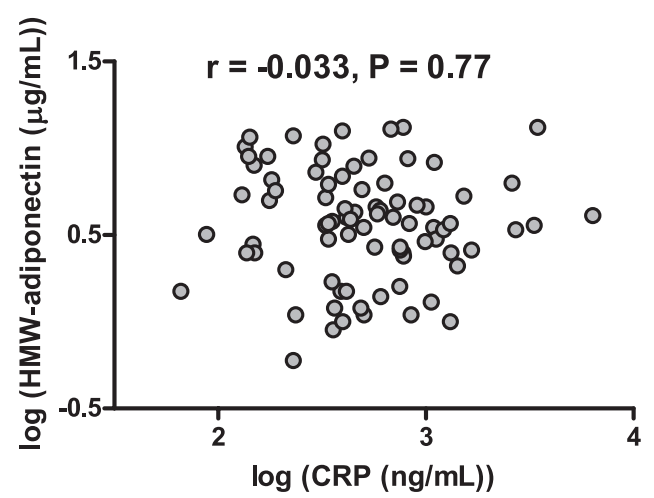

Fig. 1. Correlation between CRP and HMW-adiponectin.
Table 3. Classification by CRP and HMW-adiponectin

\begin{tabular}{ccc}
\hline CRP $(\mathrm{mg} / \mathrm{dL})$ & $\begin{array}{c}\text { HMW-adiponectin } \\
(\mu \mathrm{g} / \mathrm{mL})\end{array}$ & Score \\
\hline $0.082 \sim$ & $\sim 2.5$ & 4 \\
$0.049 \sim 0.081$ & $2.6 \sim 3.8$ & 3 \\
$0.032 \sim 0.048$ & $3.9 \sim 6.2$ & 2 \\
$\sim 0.031$ & $6.3 \sim$ & 1 \\
\hline
\end{tabular}

CRP and HMW-adiponectin were divided into four groups at 25th, 50th and 75th percentile levels.

Classification by a combination of CRP and HMW-adiponectin was defined as the sum of scores.

tion by the combination of CRP and HMW-adiponectin was defined as follows: low risk group, the sum of the scores was 2 or 3; moderate risk group, 4-6; and high risk group, 7 or 8 . The characteristics of the three classification groups are shown in Table 4. The low risk group and high risk group comprised $19 \%$ and $22 \%$ of the total patients, respectively. Among the three groups, HbA1c, LDL-cholesterol, triglycerides and HOMA-IR as well as CRP were significantly higher in the high risk group. HDL-cholesterol as well as HMW-adiponectin was significantly lower in the high risk group. Other metabolic parameters, such as BMI, blood pressure, glucose and insulin, were also higher in the high risk group than in the low risk group, while the differences did not reach statistical significance.

Comparison among the classification by CRP, HMW-adiponectin and a combination of both is shown in Table 5. Classification by CRP and HMW-adi- 
Table 4. Clinical and laboratory characteristics of three classified groups by a combination of CRP and HMW-adiponectin

\begin{tabular}{|c|c|c|c|c|c|}
\hline & & Low risk group & Moderate risk group & High risk group & $P^{\mathrm{a}}$ \\
\hline $\mathrm{N}$ & & $16(19 \%)$ & $49(59 \%)$ & $18(22 \%)$ & \\
\hline Male & $(\%)$ & 37.5 & 69.4 & 61.1 & 0.08 \\
\hline Age & (years) & $61 \pm 7$ & $63 \pm 9$ & $64 \pm 7$ & 0.51 \\
\hline Duration of diabetes & (years) & $7.5 \pm 6.7$ & $7.8 \pm 5.0$ & $8.2 \pm 5.7$ & 0.66 \\
\hline Current smoking & $(\%)$ & 25.0 & 24.5 & 44.4 & 0.26 \\
\hline BMI & $\left(\mathrm{kg} / \mathrm{m}^{2}\right)$ & $22.6 \pm 3.6$ & $23.7 \pm 3.2$ & $24.3 \pm 2.5$ & 0.21 \\
\hline Systolic blood pressure & $(\mathrm{mmHg})$ & $122 \pm 13$ & $129 \pm 17$ & $134 \pm 18$ & 0.11 \\
\hline Diastolic blood pressure & $(\mathrm{mmHg})$ & $72 \pm 11$ & $77 \pm 10$ & $80 \pm 12$ & 0.11 \\
\hline Glucose & $(\mathrm{mmol} / \mathrm{L})$ & $7.2 \pm 1.4$ & $7.7 \pm 1.5$ & $8.2 \pm 1.5$ & 0.10 \\
\hline $\mathrm{HbAlc}$ & $(\%)$ & $6.2 \pm 1.1$ & $6.3 \pm 0.8$ & $6.8 \pm 0.9$ & 0.04 \\
\hline LDL-cholesterol & $(\mathrm{mg} / \mathrm{dL})$ & $119 \pm 27$ & $117 \pm 24$ & $136 \pm 24$ & 0.03 \\
\hline HDL-cholesterol & $(\mathrm{mg} / \mathrm{dL})$ & $65 \pm 11$ & $55 \pm 12$ & $50 \pm 13$ & 0.005 \\
\hline Triglyceride & $(\mathrm{mg} / \mathrm{dL})$ & $106 \pm 80$ & $99 \pm 46$ & $131 \pm 45$ & 0.01 \\
\hline Insulin & $(\mu \mathrm{U} / \mathrm{mL})$ & $4.6 \pm 2.5$ & $7.8 \pm 6.8$ & $6.9 \pm 4.5$ & 0.05 \\
\hline HOMA-IR & - & $1.50 \pm 1.10$ & $2.67 \pm 2.41$ & $2.59 \pm 1.75$ & 0.01 \\
\hline CRP & $(\mathrm{mg} / \mathrm{dL})$ & $0.024 \pm 0.011$ & $0.074 \pm 0.101$ & $0.124 \pm 0.072$ & $<0.0001$ \\
\hline HMW-adiponectin & $(\mu \mathrm{g} / \mathrm{mL})$ & $8.5 \pm 2.4$ & $4.3 \pm 3.0$ & $2.4 \pm 0.9$ & $<0.0001$ \\
\hline
\end{tabular}

Low risk group: low CRP and high HMW-adiponectin group, High risk group: high CRP and low HMW-adiponectin group.

Values are means $\pm \mathrm{SD} .{ }^{\text {a }}$ Kruskal-Wallis test was used in analysis among three groups.

ponectin was defined as follows: low risk group, score 1 ; moderate risk group, score 2 or 3 ; and high risk group, score 4 in Table 3. Classification by CRP was significantly associated with BMI, DBP, glucose, HDL-cholesterol and triglycerides, but neither HOMA-IR nor HMW-adiponectin. Classification by HMW-adiponectin was significantly associated with glucose, HDL-cholesterol, triglycerides, insulin and
HOMA-IR, but neither blood pressure nor CRP. On the other hand, classification by a combination of CRP and $\mathrm{HMW}$-adiponectin was significantly associated with a larger number of metabolic parameters; i.e., SBP, glucose, HbA1c, LDL-cholesterol, HDL-cholesterol, triglycerides and HOMA-IR, as well as CRP and HMW-adiponectin.

Table 5. Comparison among classification by CRP, HMW-adiponectin and combination of both

\begin{tabular}{lcccccc}
\hline & & CRP & & \multicolumn{2}{c}{ HMW-adiponectin } & \multicolumn{2}{c}{ Combination } \\
& $\mathrm{r}^{\mathrm{a}}$ & $P$ & $\mathrm{r}^{\mathrm{a}}$ & $P$ & $\mathrm{r}^{\mathrm{a}}$ & \\
\hline Age & 0.034 & 0.76 & -0.012 & 0.91 & 0.110 & 0.32 \\
Sex & 0.085 & 0.44 & 0.197 & 0.07 & 0.144 & 0.19 \\
Current smoking & 0.102 & 0.35 & 0.163 & 0.14 & 0.143 & 0.19 \\
BMI & $\mathbf{0 . 2 5 0}$ & $\mathbf{0 . 0 2}$ & 0.117 & 0.29 & 0.194 & 0.08 \\
Systolic blood pressure & 0.189 & 0.09 & 0.130 & 0.24 & $\mathbf{0 . 2 2 5}$ & $\mathbf{0 . 0 4}$ \\
Diastolic blood pressure & $\mathbf{0 . 2 7 1}$ & $\mathbf{0 . 0 1}$ & 0.124 & 0.26 & 0.214 & 0.05 \\
Glucose & $\mathbf{0 . 2 3 1}$ & $\mathbf{0 . 0 4}$ & $\mathbf{0 . 2 2 4}$ & $\mathbf{0 . 0 4}$ & $\mathbf{0 . 2 3 9}$ & $\mathbf{0 . 0 3}$ \\
HbA1c & 0.173 & 0.12 & 0.139 & 0.21 & $\mathbf{0 . 2 6 7}$ & $\mathbf{0 . 0 2}$ \\
LDL-cholesterol & 0.154 & 0.16 & 0.164 & 0.14 & $\mathbf{0 . 2 2 5}$ & $\mathbf{0 . 0 4}$ \\
HDL-cholesterol & $\mathbf{- 0 . 3 3 2}$ & $\mathbf{0 . 0 0 3}$ & $-\mathbf{0 . 3 1 8}$ & $\mathbf{0 . 0 0 4}$ & $\mathbf{- 0 . 3 5 4}$ & $\mathbf{0 . 0 0 1}$ \\
Triglyceride & $\mathbf{0 . 2 6 8}$ & $\mathbf{0 . 0 2}$ & $\mathbf{0 . 2 4 6}$ & $\mathbf{0 . 0 3}$ & $\mathbf{0 . 2 9 2}$ & $\mathbf{0 . 0 0 8}$ \\
Insulin & 0.055 & 0.63 & $\mathbf{0 . 2 2 7}$ & $\mathbf{0 . 0 4}$ & 0.179 & 0.11 \\
HOMA-IR & 0.155 & 0.17 & $\mathbf{0 . 3 2 4}$ & $\mathbf{0 . 0 0 4}$ & $\mathbf{0 . 2 8 4}$ & $\mathbf{0 . 0 1}$ \\
CRP & - & & 0.070 & 0.53 & 0.679 & $<0.0001$ \\
HMW-adiponectin & -0.166 & 0.13 & - & & -0.630 & $<0.0001$ \\
\hline
\end{tabular}

a Spearman rank correlation coefficient. 


\section{Discussion}

In the present study, we investigated the efficacy of combination of CRP and HMW-adiponectin to evaluate the metabolic abnormalities in type 2 diabetic subjects. Both serum CRP and HMW-adiponectin levels were associated with several metabolic parameters in this study. However, the parameters associated with each of CRP and HMW-adiponectin were not completely consistent. Furthermore, CRP did not correlate with HMW-adiponectin. An association between CRP and adiponectin has been reported in non-diabetic [18, 23-27] and diabetic subjects [9, 20, 28-31], although others have reported no relation between CRP and adiponectin [33-35]. The lack of association between CRP and adiponectin in this study might have been due to medications affecting CRP and/or adiponectin, such as statins $[12,40]$. There was, however, no significant difference in both CRP and HMW-adiponectin levels between patients with and without statin treatment. In addition, we did not include patients treated with TZD which affects adiponectin level [41] in this study. While it has been reported that the association between CRP and adiponectin is due to an anti-inflammatory action of adiponectin itself [5], the precise mechanism of the relation between CRP and adiponectin remains to be elucidated. Shetty et al. have reported that the significant correlation of adiponectin with CRP disappeared after adjustment for sex and BMI [29]. Putz et $a l$. have reported that although CRP was significantly associated with percent fat and total fat mass, adiponectin was associated with neither of them [9]. Moreover, Matsushita et al. have reported that adiponectin showed a stronger correlation with metabolic syndrome than CRP in Japanese men [42], consistent with our finding that HMW-adiponectin rather than CRP was associated with the components of metabolic syndrome. Furthermore, recent studies have shown that CRP is associated with obesity rather than insulin resistance or metabolic syndrome [37, 38], and emerging evidence suggests a hypothesis that CRP has no causal association with metabolic syndrome [36]. Although there is little doubt about the fact that CRP and adiponectin reflect some common pathway between inflammation and insulin resistance [32], this and recent studies also suggest some different aspects between CRP and adiponectin. The different production sites between CRP and adiponectin, i.e., liver and adipose tissue, might result in some different aspects between these two markers. It will be important to characterize the subjects with discrepancies between CRP and HMW-adiponectin (i.e., high $\mathrm{CRP} /$ high HMWadiponectin or low $\mathrm{CRP} /$ low HMW-adiponectin) to understand the difference between these two markers.

Additionally, we extended this concept by showing that classification by a combination of CRP and HMWadiponectin was associated with a larger number of metabolic parameters, compared with classification by CRP or HMW-adiponectin alone, indicating that CRP and HMW-adiponectin reflect different aspects of metabolic abnormality. Interestingly, this classification was associated with not only markers of metabolic syndrome, i.e., blood pressure, glucose, HDL-cholesterol, triglycerides and HOMA-IR, which are also wellknown to be a predictor of coronary disease [43], but also classical coronary risk factors, i.e., LDL-cholesterol. It has been reported that the combination of CRP and total or LDL-cholesterol highly predicted the onset of CHD [10-12]. Furthermore, the frequency of other classical risk factors such as age and the proportion of males and current smokers were also higher in the high risk group, although the differences were not significant. We did not check other coronary risk factors such as intima-media thickness (IMT) of the carotid artery or pulse-wave velocity (PWV) in this study. However, our findings suggest the possibility that the combination of CRP and HMW-adiponectin is a highly predictive marker for patients at high risk of coronary disease in clinical settings. While the small sample size is a major limitation of our study, we could confirm similar results even when we analyzed either a subgroup of the subjects not treated with $\mathrm{SU}(\mathrm{N}=43)$ or a subgroup not treated with statins $(\mathrm{N}=66)$; i.e., (1) there was no correlation between CRP and HMW-adiponectin, (2) the combination of CRP and HMW-adiponectin was associated with a larger number of metabolic parameters compared to each of them alone (data not shown). Because we did not examine any correlation between these markers and cardiovascular events in this study, it remains unclear whether the combination of CRP and $\mathrm{HMW}$-adiponectin is more useful to predict cardiovascular events than each of them alone. The results of this study should be verified in a study with a larger sample size and a prospective study design.

In conclusion, we demonstrated that the combination of CRP and HMW-adiponectin was associated with further metabolic abnormalities in type 2 diabetic subjects compared with each of them alone. The com- 
bined measurement of both markers may be useful to detect cardiovascular high risk patients.

\section{Acknowledgements}

The authors thank Akira Shimada for helpful suggestions and Fujirebio Co. Inc. (Tokyo, Japan) for technical assistance with the ELISA system of HMWadiponectin.

\section{References}

1. Reaven GM (1988) Banting lecture 1988. Role of insulin resistance in human disease. Diabetes 37: 15951607.

2. Ross R (1999) Atherosclerosis - an inflammatory disease. N Engl J Med 340: 115-126.

3. Kannel WB, McGee DL (1979) Diabetes and cardiovascular disease. The Framingham study. JAMA 241: 2035-2038.

4. Danesh J, Whincup P, Walker M, Lennon L, Thomson A, Appleby P, et al. (2000) Low grade inflammation and coronary heart disease: prospective study and updated meta-analyses. BMJ 321: 199-204.

5. Chandran M, Phillips SA, Ciaraldi T, Henry RR (2003) Adiponectin: more than just another fat cell hormone? Diabetes Care 26: 2442-2450.

6. Visser M, Bouter LM, McQuillan GM, Wener MH, Harris TB (1999) Elevated C-reactive protein levels in overweight and obese adults. JAMA 282: 2131-2135.

7. Ford ES (1999) Body mass index, diabetes, and C-reactive protein among U.S. adults. Diabetes Care 22: 1971-1977.

8. Aronson D, Bartha P, Zinder O, Kerner A, Shitman E, Markiewicz W, et al. (2004) Association between fasting glucose and $\mathrm{C}$-reactive protein in middle-aged subjects. Diabet Med 21: 39-44.

9. Putz DM, Goldner WS, Bar RS, Haynes WG, Sivitz WI (2004) Adiponectin and C-reactive protein in obesity, type 2 diabetes, and monodrug therapy. Metabolism 53: 1454-1461.

10. Ridker PM, Hennekens CH, Buring JE, Rifai N (2000) C-reactive protein and other markers of inflammation in the prediction of cardiovascular disease in women. $N$ Engl J Med 342: 836-843.

11. Ridker PM, Rifai N, Rose L, Buring JE, Cook NR (2002) Comparison of C-reactive protein and low-density lipoprotein cholesterol levels in the prediction of first cardiovascular events. $N$ Engl J Med 347: 15571565.

12. Ridker PM, Cannon CP, Morrow D, Rifai N, Rose LM, McCabe $\mathrm{CH}$, et al. (2005) C-reactive protein levels and outcomes after statin therapy. $N$ Engl J Med 352: 2028.

13. Yatagai T, Nagasaka S, Taniguchi A, Fukushima M, Nakamura T, Kuroe A et al. (2003) Hypoadiponectine- mia is associated with visceral fat accumulation and insulin resistance in Japanese men with type 2 diabetes mellitus. Metabolism 52: 1274-1278.

14. Yamamoto Y, Hirose H, Saito I, Tomita M, Taniyama M, Matsubara K, et al. (2002) Correlation of the adipocyte-derived protein adiponectin with insulin resistance index and serum high-density lipoprotein-cholesterol, independent of body mass index, in the Japanese population. Clin Sci (Lond) 103: 137-142.

15. Yamamoto Y, Hirose H, Saito I, Nishikai K, Saruta T (2004) Adiponectin, an adipocyte-derived protein, predicts future insulin resistance: two-year follow-up study in Japanese population. J Clin Endocrinol Metab 89: 87-90.

16. Arita Y, Kihara S, Ouchi N, Takahashi M, Maeda K, Miyagawa J, et al. (1999) Paradoxical decrease of an adipose-specific protein, adiponectin, in obesity. Biochem Biophys Res Commun 257: 79-83.

17. Hotta K, Funahashi T, Arita Y, Takahashi M, Matsuda M, Okamoto Y, et al. (2000) Plasma concentrations of a novel, adipose-specific protein, adiponectin, in type 2 diabetic patients. Arterioscler Thromb Vasc Biol 20: 1595-1599.

18. Pischon T, Girman CJ, Hotamisligil GS, Rifai N, Hu FB, Rimm EB (2004) Plasma adiponectin levels and risk of myocardial infarction in men. JAMA 291: 17301737.

19. Maahs DM, Ogden LG, Kinney GL, Wadwa P, SnellBergeon JK, Dabelea D, et al. (2005) Low plasma adiponectin levels predict progression of coronary artery calcification. Circulation 111: 747-753.

20. Aso Y, Yamamoto R, Wakabayashi S, Uchida T, Takayanagi K, Takebayashi K, et al. (2006) Comparison of serum high-molecular weight (HMW) adiponectin with total adiponectin concentrations in type 2 diabetic patients with coronary artery disease using a novel enzyme-linked immunosorbent assay to detect HMW adiponectin. Diabetes 55: 1954-1960.

21. Hara K, Horikoshi M, Yamauchi T, Yago H, Miyazaki $\mathrm{O}$, Ebinuma H, et al. (2006) Measurement of the highmolecular weight form of adiponectin in plasma is useful for the prediction of insulin resistance and metabolic syndrome. Diabetes Care 29: 1357-1362.

22. Basu R, Pajvani UB, Rizza RA, Scherer PE (2007) Se- 
lective downregulation of the high-molecular weight form of adiponectin in hyperinsulinemia and in type 2 diabetes-Differential regulation from nondiabetic subjects. Diabetes 56: 2174-2177.

23. Matsubara M, Maruoka S, Katayose S (2002) Decreased plasma adiponectin concentrations in women with dyslipidemia. J Clin Endocrinol Metab 87: 2764 2769.

24. Shand BI, Scott RS, Elder PA, George PM (2003) Plasma adiponectin in overweight, nondiabetic individuals with or without insulin resistance. Diabetes Obes Metab 5: 349-353.

25. Krakoff J, Funahashi T, Stehouwer CD, Schalkwijk CG, Tanaka S, Matsuzawa Y, et al. (2003) Inflammatory markers, adiponectin, and risk of type 2 diabetes in the Pima Indian. Diabetes Care 26: 1745-1751.

26. Engeli S, Feldpausch M, Gorzelniak K, Hartwig F, Heintze U, Janke J, et al. (2003) Association between adiponectin and mediators of inflammation in obese women. Diabetes 52: 942-947.

27. Matsushita K, Yatsuya H, Tamakoshi K, Wada K, Otsuka R, Zhang H, et al. (2006) Inverse association between adiponectin and C-reactive protein in substantially healthy Japanese men. Atherosclerosis 188: 184189.

28. Schulze MB, Rimm EB, Shai I, Rifai N, Hu FB (2004) Relationship between adiponectin and glycemic control, blood lipids, and inflammatory markers in men with type 2 diabetes. Diabetes Care 27: 1680-1687.

29. Shetty GK, Economides PA, Horton ES, Mantzoros CS, Veves A (2004) Circulating adiponectin and resistin levels in relation to metabolic factors, inflammatory markers, and vascular reactivity in diabetic patients and subjects at risk for diabetes. Diabetes Care 27: 24502457.

30. Mantzoros CS, Li T, Manson JE, Meigs JB, Hu FB (2005) Circulating adiponectin levels are associated with better glycemic control, more favorable lipid profile, and reduced inflammation in women with type 2 diabetes. J Clin Endocrinol Metab 90: 4542-4548.

31. Yuan G, Zhou L, Tang J, Yang Y, Gu W, Li F, et al. (2006) Serum CRP levels are equally elevated in newly diagnosed type 2 diabetes and impaired glucose tolerance and related to adiponectin levels and insulin sensitivity. Diabetes Res Clin Pract 72: 244-250.

32. Van Gaal LF, Mertens IL, De Block CE (2006) Mechanisms linking obesity with cardiovascular disease. Nature 444: 875-880.

33. Behre CJ, Fagerberg B, Hulten LM, Hulthe J (2005) The reciprocal association of adipocytokines with insulin resistance and C-reactive protein in clinically healthy men. Metabolism 54: 439-444.
34. Abbasi F, Farin HM, Lamendola C, McLaughlin T, Schwartz EA, Reaven GM, et al. (2006) The relationship between plasma adiponectin concentration and insulin resistance is altered in smokers. J Clin Endocrinol Metab 91: 5002-5007.

35. Dvorakova-Lorenzova A, Suchanek P, Havel PJ, Stavek P, Karasova L, Valenta Z, et al. (2006) The decrease in C-reactive protein concentration after diet and physical activity induced weight reduction is associated with changes in plasma lipids, but not interleukin- 6 or adiponectin. Metabolism 55: 359-365.

36. Timpson NJ, Lawlor DA, Harbord RM, Gaunt TR, Day IN, Palmer LJ, et al. (2005) C-reactive protein and its role in metabolic syndrome: mendelian randomisation study. Lancet 366: 1954-1959.

37. Aronson D, Bartha P, Zinder O, Kerner A, Markiewicz W, Avizohar O, et al. (2004) Obesity is the major determinant of elevated C-reactive protein in subjects with the metabolic syndrome. Int J Obes Relat Metab Disord 28: 674-679.

38. Kahn SE, Zinman B, Haffner SM, O’Neill MC, Kravitz $\mathrm{BG}, \mathrm{Yu} \mathrm{D}$, et al. (2006) Obesity is a major determinant of the association of C-reactive protein levels and the metabolic syndrome in type 2 diabetes. Diabetes 55 : 2357-2364.

39. Nakano Y, Tajima S, Yoshimi A, Akiyama H, Tsushima M, Tanioka T, et al. (2006) A novel enzymelinked immunosorbent assay specific for high-molecular-weight adiponectin. J Lipid Res 47: 1572-1582.

40. Sakamoto K, Sakamoto T, Ogawa H (2006) Kumamoto Joint Research on Hypercholesterolemia (KOJIROH) Investigators, The effect of 6 months of treatment with pravastatin on serum adiponectin concentrations in Japanese patients with coronary artery disease and hypercholesterolemia: a pilot study. Clin Ther 28: 1012-1021.

41. Hirose H, Kawai T, Yamamoto $Y$, Taniyama M, Tomita M, Matsubara K, et al. (2002) Effects of pioglitazone on metabolic parameters, body fat distribution, and serum adiponectin levels in Japanese male patients with type 2 diabetes. Metabolism 51: 314-317.

42. Matsushita K, Yatsuya H, Tamakoshi K, Wada K, Otsuka R, Takefuji S, et al. (2006) Comparison of circulating adiponectin and proinflammatory markers regarding their association with metabolic syndrome in Japanese men. Arterioscler Thromb Vasc Biol 26: 871876.

43. Lakka HM, Laaksonen DE, Lakka TA, Niskanen LK, Kumpusalo E, Tuomilehto J, et al. (2002) The metabolic syndrome and total and cardiovascular disease mortality in middle-aged men. JAMA 288: 2709-2716. 